Article

\title{
Synergy Effects in Electromagnetic Properties of Phosphate Ceramics with Silicon Carbide Whiskers and Carbon Nanotubes
}

\author{
Artyom Plyushch ${ }^{1,2}$, Jan Macutkevič ${ }^{1}$, Polina Kuzhir ${ }^{2,3, *}{ }^{1}$, Aliaksei Sokal ${ }^{4}$, \\ Konstantin Lapko ${ }^{4}$, Algirdas Selskis ${ }^{5}$ and Jūras Banys ${ }^{1}$ \\ 1 Faculty of Physics, Vilnius University, Sauletekio 9, LT-10222 Vilnius, Lithuania; \\ artyom.plyushch@ff.vu.lt (A.P.); jan.macutkevic@gmail.com (J.M.); juras.banys@ff.vu.lt (J.B.) \\ 2 Institute for Nuclear Problems, Belarusian State University, 220006 Minsk, Belarus \\ 3 Institute of Photonics, University of Eastern Finland, Yliopistokatu 7, FI-80101 Joensuu, Finland \\ 4 Belarusian State University, Research Institute of Physical and Chemical Problems, BSU NEIL Inorganic \\ and General Chemistry, 14 Leningradskaya Str., 220030 Minsk, Belarus; sokolaa@bsu.by (A.S.); \\ lapkokn@bsu.by (K.L.) \\ 5 Center for Physical Sciences and Technology, Sauletekio 3, 10257 Vilnius, Lithuania; algirdas.selskis@ftmc.lt \\ * Correspondence: polina.kuzhir@uef.fi or kuzhir@bsu.by; Tel.: +358-505-666-624
}

Received: 16 September 2019; Accepted: 14 October 2019; Published: 17 October 2019

\begin{abstract}
Hybrid composite materials based on an aluminium phosphate matrix with silicon carbide whiskers and multi-walled carbon nanotubes were studied in a wide frequency range ( $20 \mathrm{~Hz}$ to $36 \mathrm{GHz}$ ). It was demonstrated, that the addition of the silicon carbide whiskers enhances the dielectric permittivity and conductivity. This was explained by the difference in tunnelling parameters. Hybrid ceramics with nanotubes and whiskers also exhibits substantially improved electromagnetic shielding properties. The hybrid ceramics with $10 \mathrm{wt}$. \% silicon carbide whiskers and a $1 \mathrm{~mm}$ thick $1.5 \mathrm{wt}$. \% carbon nanotube layer, show higher than $50 \%$ absorption of electromagnetic radiation.
\end{abstract}

Keywords: hybrid composite; carbon nanotube; $\mathrm{SiC}$ whisker; dielectric properties; shielding properties

\section{Introduction}

Composite materials are widely used in several engineering applications, including biomedical [1], aerospace [2], and specific electromagnetic [3,4]. For the researchers composites are especially interesting because their features drastically depend on the preparation technique and the initial compounds' properties [5-7]. Another appealing aspect is the theoretical and numerical modelling of composites as ordered, for instance layered [8,9], corrugated [10], or disordered [11,12] media.

Composites filled with more than one type of inclusions, or hybrid composites, have received a good deal of attention in recent decades [13-15]. This is because, on the one hand, the combination of fillers provides the multifunctional materials with advanced properties in comparison with one-type filled conterpartners $[16,17]$. On the other hand, the interaction between fillers may determine the synergetic effects [18,19]. In the case of multi-walled carbon nanotubes (MWCNT), the frequent choice of the second filler is graphene nanoplatelets or graphene oxide [20-23], which allows the combination of different shielding properties [24]. At the same time, composites filled with a combination of carbonaceous and inorganic inclusions have been given less recognition $[25,26]$.

In the meantime, for practical applications, the high hardness, good wear and corrosion resistance of ceramics matrices are important (for example alumina, $\mathrm{Al}_{2} \mathrm{O}_{3}$ ), which makes them attractive for further investigations. In particular, it has been demonstrated that MWCNT/alumina phosphate 
composites show advanced thermal, mechanical, and electrical properties in comparison with polymer-based composites [27,28].

The addition of $\mathrm{SiC}$ nanoparticles results in substantially improved mechanical properties of ceramics [29]. Ceramics with $\mathrm{SiC}$ also exhibit good microwave shielding properties [30].

However, the investigations of the electromagnetic properties of hybrid ceramics with carbon and $\mathrm{SiC}$ nanoinclusions are rather rare [31]. The aim of this paper is to investigate the electromagnetic properties of aluminium phosphate-based ceramics with carbon nanotubes (CNT) and $\mathrm{SiC}$ nanoinclusions and to find the synergy effect, if any.

The paper is organised in the following way: firstly we discuss in detail the sample preparation procedure; next the dielectric permittivity of the hybrid and one-component samples in wide frequency range is presented with the focus on the comparison at low frequencies. Finally, we present the numerical approach for the shielding properties calculation for the free-standing film in the $\mathrm{GHz}$ range and compare the results with experimentally measured data. The impact of SiC loading is discussed both for the low frequency and GHz ranges.

\section{Experimental}

MWCNT were synthesized via the chemical vapor deposition (CVD) method. Aligned MWCNT arrays were grown on silicon substrates as a result of the thermal decomposition of toluene at a temperature of $800^{\circ} \mathrm{C}$. The preparation method details can be found in [32], for example, and scanning and tunnelling electron microscopy of the nanotubes used have been presented in our previous works [27,33].

Commercially available [34] silicon carbide whiskers were used for ceramics preparation. Whiskers have a diameter less than $2.5 \mu \mathrm{m}$, and the average length of 50-80 $\mu \mathrm{m}$.

Aluminium phosphate ceramic matrices are made of two components: A filler is a homogeneous mixture of $\mathrm{Al}_{2} \mathrm{O}_{3}$ and $\mathrm{AlN}$ with mass ratio $\mathrm{m}\left(\mathrm{Al}_{2} \mathrm{O}_{3}\right): \mathrm{m}(\mathrm{AlN})=9: 1$, and a binder, a dissolution of the aluminium hydroxide in a diluted phosphoric acid with a mass fraction of $60 \%$. The molar ratio of $\mathrm{H}_{3} \mathrm{PO}_{4} / \mathrm{Al}(\mathrm{OH})_{3}$ is equal to 3 . A binder and filler were mixed together and a $10 \mathrm{~mm}$ diameter, $1 \mathrm{~mm}$ and $2 \mathrm{~mm}$ thick tablets were formed. After $24 \mathrm{~h}$ treatment at ambient conditions, samples were heated to $300^{\circ} \mathrm{C}$.

During the mixing procedure MWCNTs and $\mathrm{SiC}$ whiskers were added and a series of hybrid samples with $10 \mathrm{wt}$. \% of SiC, and 0.5, 1, 1.5, 2 wt. \% of MWCNT was prepared. For comparison, a second series filled only with MWCNTs of the same fraction was fabricated (see Figure 1).
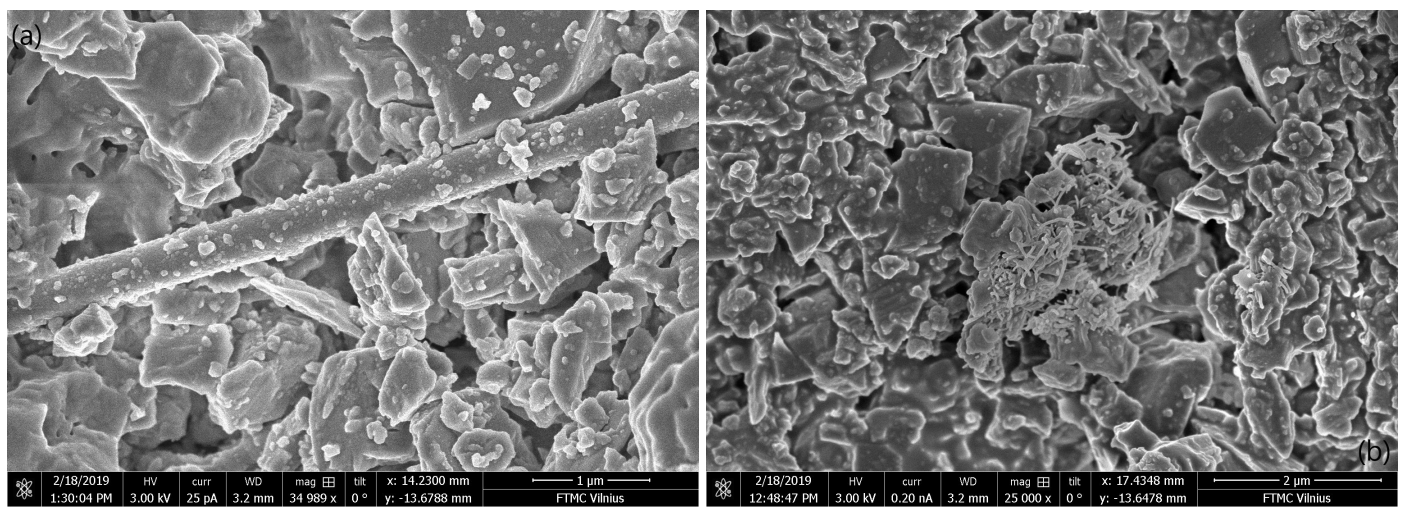

Figure 1. Scanning electron microscopy of the sample: SiC whiskers (a) and (b) MWCNTs embedded into phosphate martix.

Frequency dependencies of complex dielectric permittivity were measured using an HP4284A precision LCR meter in the frequency range $20 \mathrm{~Hz}-1 \mathrm{MHz}$, by a vector network analyser Agilent $8714 \mathrm{ET}$ in the frequency range $1 \mathrm{MHz}-3 \mathrm{GHz}$, and using a waveguide technique with a scalar network 
analyser R2-408R (ELMIKA, Vilnius, Lithuania) in the range of 26-37 GHz. The real part of complex electrical conductivity $\sigma^{\prime}$ was calculated as $\sigma=\omega \varepsilon_{0} \varepsilon^{\prime \prime}$, where $\varepsilon_{0}$ is the permittivity of vacuum.

\section{Results and Discussion}

\subsection{Radio Frequency Range}

Typical frequency dependencies of dielectric permittivity and electrical conductivity for ceramics loaded with MWCNTs and hybrid MWCNT + SiC whiskers inclusions are presented in Figure 2. The frequency dependence of these parameters is caused by low frequency dispersion $[35,36]$, which is typical for the disordered media. At low frequencies (below $129 \mathrm{~Hz}$ ) the dielectric permittivity is high (higher than 100) for all the investigated samples.
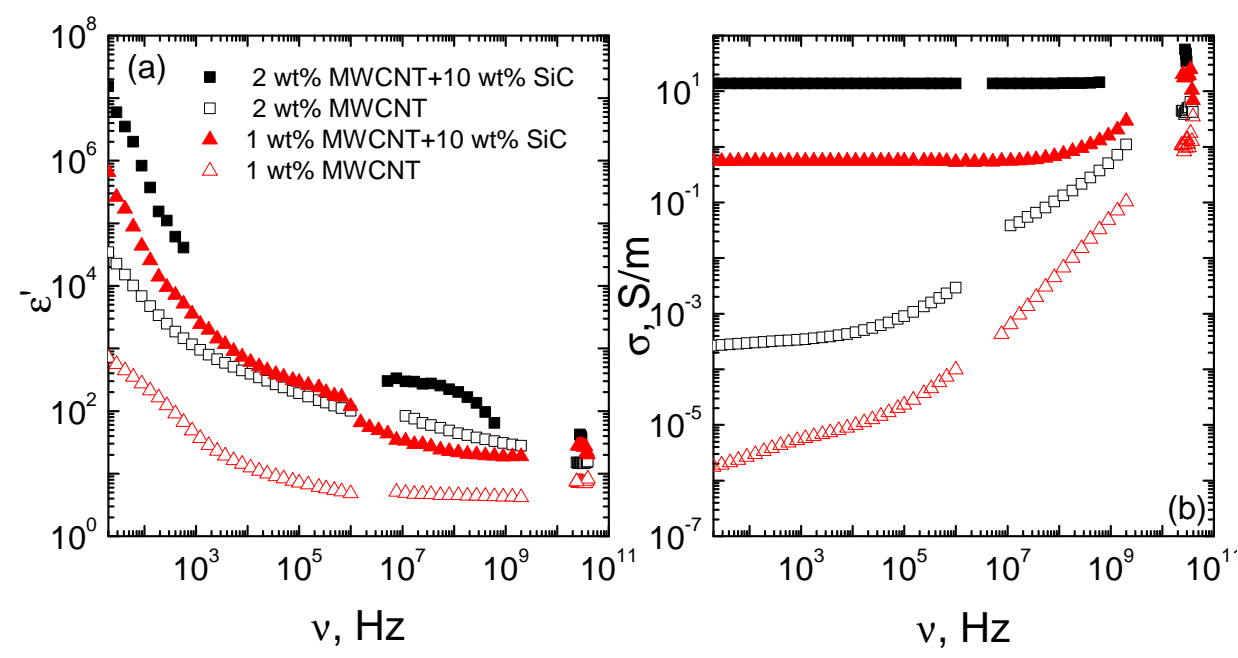

Figure 2. Comparison of (a) dielectric permittivity and (b) conductivity of the hybrid samples and MWCNT-filled samples as a function of frequency.

The SiC whiskers addition leads to a significant increase of the permittivity and conductivity of the composites (see Figure 3). The percolation threshold in both types of ceramic based samples is near $0.5 \mathrm{wt}$. \%. Particularly above the percolation threshold, the DC conductivity of hybrid composites is five orders of magnitude higher than the conductivity of composites filled only with MWCNT inclusions. Moreover, the dielectric permittivity at $129 \mathrm{~Hz}$ is at least 1000 times higher for hybrid composites than that of composites filled only with MWCNT.
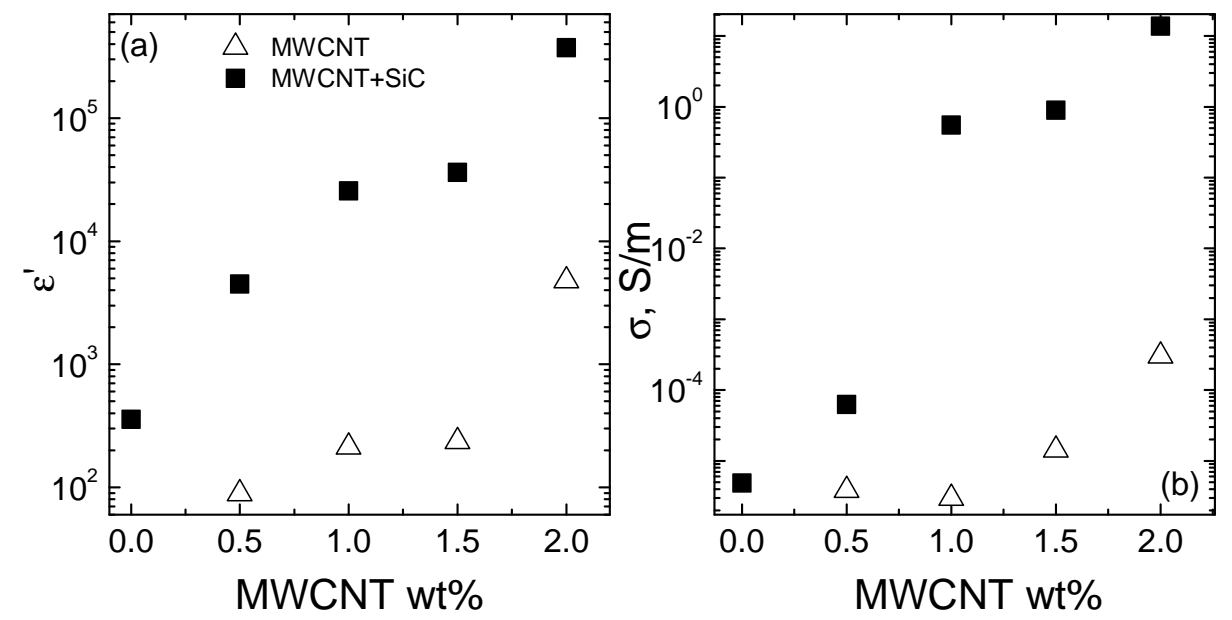

Figure 3. Dielectric permittivity (a) and (b) conductivity of the hybrid samples and MWCNT-filled samples as a function of MWCNT concentration at the fixed frequency of $129 \mathrm{~Hz}$. 
It was previously demonstrated, that the $\mathrm{SiC}$ whiskers/ceramics composites have a percolation threshold at a concentration of $25 \mathrm{wt}$. \%. That is the addition of $10 \mathrm{wt}$. \% of $\mathrm{SiC}$ would not create a percolation network.

To understand the underlying physics the following idea may be proposed. It has been proven, that the conductivity of the MWCNT/ceramic composites has the tunnelling mechanism [33]. The tunnelling resistivity between two equivalent nanotubes can be calculated using the equation [37]:

$$
\rho=\frac{h^{2}}{e^{2} \sqrt{2 m \lambda}} \exp \left(\frac{4 \pi d}{h} \sqrt{2 m \lambda}\right)
$$

where $\lambda$ is the potential barrier, and $d$ is the separation distance. Next, if we add the $\mathrm{SiC}$ whiskers in the system it should affect both $\lambda$ and $d$. When these values decrease, the total conductivity of the sample should increase drastically. To prove this idea, the low temperature measurements of the conductivity of the ceramics loaded with $2 \mathrm{wt}$. \% MWCNT $+10 \mathrm{wt}$ \% SiC and $2 \mathrm{wt}$. \% MWCNT was done. The temperature dependences of the conductivity for the hybrid and one-component composites are presented in Figure 4.

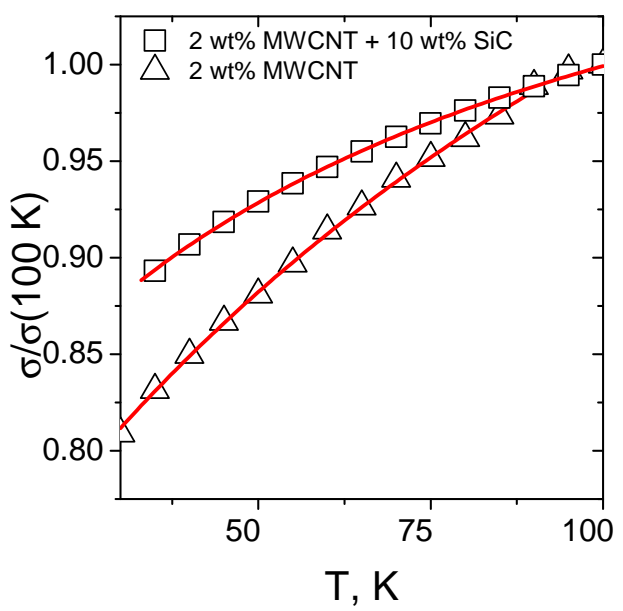

Figure 4. Relative conductivity $(\sigma / \sigma(100 \mathrm{~K}))$ dependence on the temperature (symbols); fit with the tunnelling law (solid lines).

The measured experimental data can be fitted with the tunnelling law for both cases as one-component and hybrid composites [38]:

$$
\sigma_{D C}=\sigma_{0} e^{-\frac{T_{1}}{T+T_{0}}}
$$

Here $T_{1}$ is the energy required for an electron to cross the gap between two conductive particles, and $T_{0}$ is the temperature above which the thermally activated conduction over the barriers begins to occur. The values of the $T_{1}$ and $T_{0}$ are related to the microstructure of the composite samples, and their ratio reads as $T_{1} / T_{0}=(\pi / 2) \sqrt{2 m_{e} / \hbar} \lambda^{1 / 2} d \sim \lambda^{1 / 2} d$. The obtained values for the $T_{1} / T_{0}$ are 0.783 and 0.435 for the one-component and hybrid composite correspondingly. This difference proves that the tunnelling potential barrier and/or separation distance is lower for the hybrid composite. The increase of the tunnelling conductivity should also affect the percolation concentration value, but due to the finite number of sample's concentrations, it is difficult to determine it precisely.

\subsection{GHz Shielding Properties}

In the microwave frequency range both real and imaginary parts of the permittivity do not demonstrate any significant frequency dispersion. Both of them increase with the concentration for the one-component and hybrid composites. 
In order to check the shielding properties of the produced samples the following method was used. Let us consider a thin planar layer in the free space with the electromagnetic irradiation incident perpendicularly. The scattering parameters for such system are given by the equations [39]:

$$
\left\{\begin{array}{l}
S_{11}=\frac{-j\left[\left(k_{z} / k_{2 z}\right)^{2}-1\right] \sin \left(k_{2 z} \tau\right)}{2 j\left(k_{z} / k_{2 z}\right) \cos \left(k_{2 z} \tau\right)+\left[\left(k_{z} / k_{2 z} z\right)^{2}+1\right] \sin \left(k_{2 z} \tau\right)} \\
S_{21}=\frac{2\left(k_{2 z} / k_{z}\right)}{-2\left(k_{2 z} / k_{z}\right) \cos \left(k_{2 z} \tau\right)+j\left[\left(k_{2 z} / k_{z}\right)^{2}+1\right] \sin \left(k_{2 z} \tau\right)}
\end{array},\right.
$$

where $k_{z}=2 \pi / \lambda$ and $k_{2 z}=2 \pi \sqrt{\varepsilon} / \lambda$ are wave numbers in the vacuum and the sample's media correspondingly, and $\tau$ is the thickness of the layer. The absorption of the layer may be computed as $A=1-\left(S_{11}^{T}\right)^{2}-\left(S_{21}^{T}\right)^{2}$. We obtain absorption of the planar layer as a function of the irradiation frequency, sample thickness and the complex dielectric permittivity of the sample, $A=A\left(\nu, \tau, \varepsilon^{*}\right)$. To simplify the complex function we can take fixed frequency and sample thickness as $v_{0}=30 \mathrm{GHz}$, $\tau_{0}=1 \mathrm{~mm}$. The results are presented in Figure 5 as a dependence of the absorption on the real and imaginary parts of permittivity.

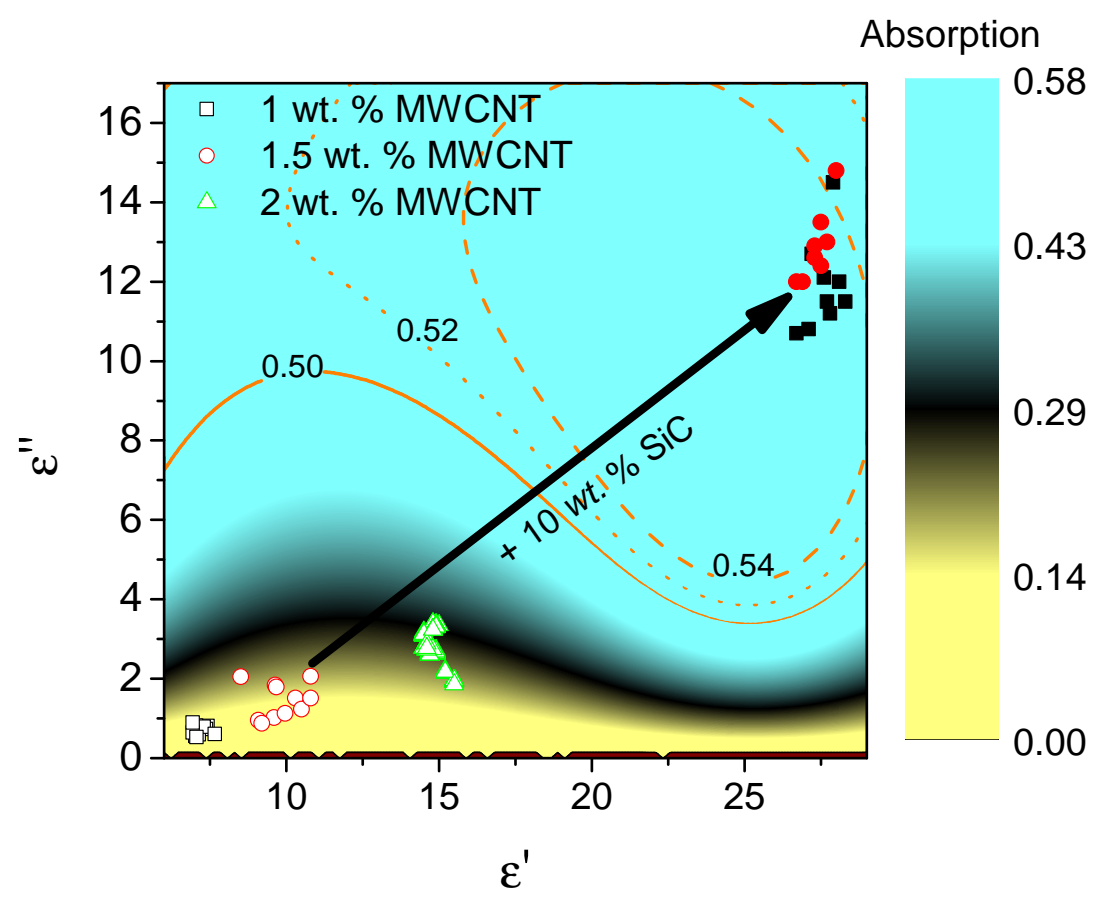

Figure 5. Electromagnetic irradiation $(30 \mathrm{GHz}$ ) absorption of the planar $1 \mathrm{~mm}$ layer plotted as a function of dielectric permittivity. Dots presents the experimentally measured values of the permittivity for the pure MWCNT (open) and hybrid, SiC + MWCNT composites.

The addition of the $\mathrm{SiC}$ whiskers strongly improves the absorption and its value reaches $56 \%$. In contrast to highly reflective composites filled only with MWCNTs [40], hybrid SiC + MWCNT composites provide shielding mostly by means of absorption.

\section{Conclusions}

Hybrid composite materials based on an aluminium phosphate matrix with $\mathrm{SiC}$ whiskers and multi-walled carbon nanotubes were studied in a wide frequency range ( $20 \mathrm{~Hz}$ to $36 \mathrm{GHz})$. Although the electrical percolation threshold is not lower in hybrid MWCNT/SiC ceramics in comparison with one-component MWCNT filled ceramics, the broadband electromagnetic properties of ceramics are substantially improved by the addition of $\mathrm{SiC}$ whiskers. Particularly close and above the percolation 
threshold, the DC conductivity of hybrid composites is $10^{5}$ times higher than the DC conductivity of composites filled only with the MWCNT inclusions and the dielectric permittivity at $129 \mathrm{~Hz}$ is at least 1000 times higher for hybrid composites than for one-component composites loaded with MWCNT of the same concentration. The difference was explained with the decrease of the tunnelling separation and/or the potential barrier value. Hybrid ceramics with MWCNT and SiC whiskers also exhibit substantially improved electromagnetic shielding properties. The hybrid ceramics with 10 wt. \% of SiC whiskers and a $1 \mathrm{~mm}$ thick $1.5 \mathrm{wt}$. \% MWCNT layer, show more than $54 \%$ absorption of electromagnetic radiation, whereas the addition of just $1.5 \mathrm{wt}$. \% of MWCNT leads to only $10 \%$.

Author Contributions: A.S. (Aliaksei Sokal) and K.L., ceramic sample preparation; J.M., radiofrequency characterization, writing the draft; A.P., GHz frequency characterisation, writing the draft; A.S. (Algirdas Selskis), scanning electron spectroscopy of the samples; P.K., writing the final paper; J.B., conceptualization.

Acknowledgments: The work is supported by H2020 RISE 734164 Graphene 3D. P.K. acknowledges the financial support from H2020-MSCA-IF-2018 project 836816 TURANDOT.

Conflicts of Interest: The authors declare no conflict of interest.

\section{Abbreviations}

The following abbreviations are used in this manuscript:

MWCNT multi-walled carbon nanotube

CVD chemical vapor deposition

\section{References}

1. Ramakrishna, S.; Mayer, J.; Wintermantel, E.; Leong, K.W. Biomedical applications of polymer-composite materials: A review. Compos. Sci. Technol. 2001, 61, 1189-1224. [CrossRef]

2. Mangalgiri, P. Composite materials for aerospace applications. Bull. Mater. Sci. 1999, 22, 657-664. [CrossRef]

3. Kong, L.; Li, Z.; Liu, L.; Huang, R.; Abshinova, M.; Yang, Z.; Tang, C.; Tan, P.; Deng, C.; Matitsine, S. Recent progress in some composite materials and structures for specific electromagnetic applications. Int. Mater. Rev. 2013, 58, 203-259. [CrossRef]

4. Dusastre, V.; Kilner, J. Optimisation of composite cathodes for intermediate temperature SOFC applications. Solid State Ion. 1999, 126, 163-174. [CrossRef]

5. Keteklahijani, Y.Z.; Arjmand, M.; Sundararaj, U. Cobalt catalyst grown carbon nanotube/poly (vinylidene fluoride) nanocomposites: Effect of synthesis temperature on morphology, electrical conductivity and electromagnetic interference shielding. ChemistrySelect 2017, 2, 10271-10284. [CrossRef]

6. Arjmand, M.; Mahmoodi, M.; Park, S.; Sundararaj, U. Impact of foaming on the broadband dielectric properties of multi-walled carbon nanotube/polystyrene composites. J. Cell. Plast. 2014, 50, 551-562. [CrossRef]

7. Mirkhani, S.A.; Arjmand, M.; Sadeghi, S.; Krause, B.; Pötschke, P.; Sundararaj, U. Impact of synthesis temperature on morphology, rheology and electromagnetic interference shielding of CVD-grown carbon nanotube/polyvinylidene fluoride nanocomposites. Synth. Met. 2017, 230, 39-50. [CrossRef]

8. Funari, M.F.; Greco, F.; Lonetti, P. Dynamic debonding in layered structures: A coupled ALE-cohesive approach. Frat. Ed Integrità Strutt. 2017, 11, 524-535. [CrossRef]

9. Funari, M.F.; Greco, F.; Lonetti, P.; Spadea, S. A numerical model based on ALE formulation to predict crack propagation in sandwich structures. Frat. Ed Integrità Strutt. 2019, 13, 277-293. [CrossRef]

10. Bychanok, D.; Plyushch, A.; Gorokhov, G.; Bychanok, U.; Kuzhir, P.; Maksimenko, S. Microwave radiation absorbers based on corrugated composites with carbon fibers. Tech. Phys. 2016, 61, 1880-1884. [CrossRef]

11. Plyushch, A.; Lamberti, P.; Spinelli, G.; Macutkevič, J.; Kuzhir, P. Numerical simulation of the percolation threshold in non-overlapping ellipsoid composites: Toward bottom-up approach for carbon based electromagnetic components realization. Appl. Sci. 2018, 8, 882. [CrossRef]

12. Grimmett, G. What is Percolation? In Percolation; Springer: Berlin/Heidelberg, Germany, 1999; pp. 1-31.

13. Xia, Z.; Riester, L.; Curtin, W.; Li, H.; Sheldon, B.; Liang, J.; Chang, B.; Xu, J. Direct observation of toughening mechanisms in carbon nanotube ceramic matrix composites. Acta Mater. 2004, 52, 931-944. [CrossRef] 
14. Chatterjee, S.; Nafezarefi, F.; Tai, N.; Schlagenhauf, L.; Nüesch, F.; Chu, B. Size and synergy effects of nanofiller hybrids including graphene nanoplatelets and carbon nanotubes in mechanical properties of epoxy composites. Carbon 2012, 50, 5380-5386. [CrossRef]

15. Zhou, T.; Wang, X.; Liu, X.; Xiong, D. Improved thermal conductivity of epoxy composites using a hybrid multi-walled carbon nanotube/micro-SiC filler. Carbon 2010, 48, 1171-1176. [CrossRef]

16. Yu, A.; Ramesh, P.; Sun, X.; Bekyarova, E.; Itkis, M.E.; Haddon, R.C. Enhanced thermal conductivity in a hybrid graphite nanoplatelet-carbon nanotube filler for epoxy composites. Adv. Mater. 2008, 20, 4740-4744. [CrossRef]

17. Li, W.; Dichiara, A.; Bai, J. Carbon nanotube-graphene nanoplatelet hybrids as high-performance multifunctional reinforcements in epoxy composites. Compos. Sci. Technol. 2013, 74, 221-227. [CrossRef]

18. Yu, J.; Choi, H.K.; Kim, H.S.; Kim, S.Y. Synergistic effect of hybrid graphene nanoplatelet and multi-walled carbon nanotube fillers on the thermal conductivity of polymer composites and theoretical modeling of the synergistic effect. Compos. Part A Appl. Sci. Manuf. 2016, 88, 79-85. [CrossRef]

19. Qiu, L.; Yang, X.; Gou, X.; Yang, W.; Ma, Z.F.; Wallace, G.G.; Li, D. Dispersing carbon nanotubes with graphene oxide in water and synergistic effects between graphene derivatives. Chem. Eur. J. 2010, 16, 10653-10658. [CrossRef]

20. Dichiara, A.B.; Sherwood, T.J.; Rogers, R.E. Binder free graphene-single-wall carbon nanotube hybrid papers for the removal of polyaromatic compounds from aqueous systems. J. Mater. Chem. A 2013, 1, 14480-14483. [CrossRef]

21. Joseph, J.; Munda, P.R.; John, D.A.; Sidpara, A.M.; Paul, J. Graphene and CNT filled hybrid thermoplastic composites for enhanced EMI shielding effectiveness. Mater. Res. Express 2019, 6, 085617. [CrossRef]

22. Aghadavoudi, F.; Golestanian, H.; Zarasvand, K.A. Elastic behaviour of hybrid cross-linked epoxy-based nanocomposite reinforced with GNP and CNT: Experimental and multiscale modelling. Polym. Bull. 2019, 76, 4275-4294. [CrossRef]

23. Yue, L.; Pircheraghi, G.; Monemian, S.A.; Manas-Zloczower, I. Epoxy composites with carbon nanotubes and graphene nanoplatelets-Dispersion and synergy effects. Carbon 2014, 78, 268-278. [CrossRef]

24. Arjmand, M.; Sadeghi, S.; Otero Navas, I.; Zamani Keteklahijani, Y.; Dordanihaghighi, S.; Sundararaj, U. Carbon Nanotube versus Graphene Nanoribbon: Impact of Nanofiller Geometry on Electromagnetic Interference Shielding of Polyvinylidene Fluoride Nanocomposites. Polymers 2019, 11, 1064. [CrossRef]

25. Shajari, S.; Arjmand, M.; Pawar, S.P.; Sundararaj, U.; Sudak, L.J. Synergistic effect of hybrid stainless steel fiber and carbon nanotube on mechanical properties and electromagnetic interference shielding of polypropylene nanocomposites. Compos. Part B Eng. 2019, 165, 662-670. [CrossRef]

26. Khajehpour, M.; Arjmand, M.; Sundararaj, U. Dielectric properties of multiwalled carbon nanotube/ clay/polyvinylidene fluoride nanocomposites: Effect of clay incorporation. Polym. Compos. 2016, 37, 161-167. [CrossRef]

27. Apanasevich, N.; Sokal, A.; Lapko, K.; Kudlash, A.; Lomonosov, V.; Plyushch, A.; Kuzhir, P.; Macutkevic, J.; Banys, J.; Okotrub, A. Phosphate ceramics-carbon nanotubes composites: Liquid aluminum phosphate vs. solid magnesium phosphate binder. Ceram. Int. 2015, 41, 12147-12152. [CrossRef]

28. Plyushch, A.; Bychanok, D.; Kuzhir, P.; Maksimenko, S.; Lapko, K.; Sokol, A.; Macutkevic, J.; Banys, J.; Micciulla, F.; Cataldo, A.; et al. Heat-resistant unfired phosphate ceramics with carbon nanotubes for electromagnetic application. Phys. Status Solidi A 2014, 211, 2580-2585. [CrossRef]

29. O'Sullivan, D.; Hampshire, S.; Kennedy, T. Fabrication, properties, and modelling of engineering ceramics reinforced with nanoparticles of silicon carbide. Br. Ceram. Trans. 1997, 96, 121-127.

30. Duan, W.; Yin, X.; Li, Q.; Liu, X.; Cheng, L.; Zhang, L. Synthesis and microwave absorption properties of SiC nanowires reinforced SiOC ceramic. J. Eur. Ceram. Soc. 2014, 34, 257-266. [CrossRef]

31. Han, M.; Yin, X.; Duan, W.; Ren, S.; Zhang, L.; Cheng, L. Hierarchical graphene/SiC nanowire networks in polymer-derived ceramics with enhanced electromagnetic wave absorbing capability. J. Eur. Ceram. Soc. 2016, 36, 2695-2703. [CrossRef]

32. Okotrub, A.V.; Bulusheva, L.G.; Kudashov, A.G.; Belavin, V.V.; Komogortsev, S.V. Arrays of carbon nanotubes aligned perpendicular to the substrate surface: Anisotropy of structure and properties. Nanotechnol. Russ. 2008, 3, 191-200. [CrossRef] 
33. Plyushch, A.; Kuzhir, P.P.; Maksimenko, S.A.; Macutkevič, J.; Banys, J.; Sokal, A.; Lapko, K.N.; Arkhipov, V.; Okotrub, A. Grain size effect in conductive phosphate/carbon nanotube ceramics. Ceram. Int. 2017, 43, 4965-4969. [CrossRef]

34. Available online: www.us-nano.com (accessed on 16 September 2019).

35. Dissado, L.A.; Hill, R.M. Anomalous low-frequency dispersion. Near direct current conductivity in disordered low-dimensional materials. J. Chem. Soc. Faraday Trans. 2 Mol. Chem. Phys. 1984, 80, 291-319. [CrossRef]

36. Jonscher, A. Low-frequency dispersion in carrier-dominated dielectri. Philos. Mag. B 1978, 38, 587-601. [CrossRef]

37. Simmons, J.G. Generalized formula for the electric tunnel effect between similar electrodes separated by a thin insulating film. J. Appl. Phys. 1963, 34, 1793-1803. [CrossRef]

38. Sheng, P.; Sichel, E.K.; Gittleman, J.I. Fluctuation-Induced Tunneling Conduction in Carbon-Polyvinylchloride Composites. Phys. Rev. Lett. 1978, 40, 1197-1200. [CrossRef]

39. Chen, L.F.; Ong, C.; Neo, C.; Varadan, V.; Varadan, V.K. Microwave Electronics: Measurement and Materials Characterization; John Wiley \& Sons: Chichester, West Sussex, UK, 2004.

40. Kanygin, M.; Sedelnikova, O.; Asanov, I.; Bulusheva, L.; Okotrub, A.; Kuzhir, P.; Plyushch, A.; Maksimenko, S.; Lapko, K.; Sokol, A.; et al. Effect of nitrogen doping on the electromagnetic properties of carbon nanotube-based composites. J. Appl. Phys. 2013, 113, 144315. [CrossRef]

(C) 2019 by the authors. Licensee MDPI, Basel, Switzerland. This article is an open access article distributed under the terms and conditions of the Creative Commons Attribution (CC BY) license (http://creativecommons.org/licenses/by/4.0/). 